healing. The irregularity of ulcer shape means there is no direct relation between ulcer diameter and area. Nevertheless, either method can be used to calculate the prognostic index and both are included as alternatives for scoring in table III.

The presence of bacterial contamination seems to be of little relevance to venous ulcer healing. ${ }^{15} \mathrm{We}$ found no association between bacteria present at the start of the trial and ulcer healing. However, we also observed that the bacteria present change from month to month. This agrees with Ormiston et al, who found no consistent trend towards eradication of particular pathogens irrespective of the treatment or response of the ulcers. ${ }^{16}$

It seems logical to recommend that the four identified factors should be taken into consideration in the future when comparing methods of treatment. The prognostic index score can be used to stratify patients into high, medium, and low risk groups. This would make the treatment groups more comparable. Alternatively, all four prognostic factors could be incorporated into the model when assessing treatment effects. The prognostic index has been derived and verified on the same data. A repeat study may not obtain as clear a graduation of patients as shown in table IV.

The prognostic index is also valuable for individual patients. If the probability of the ulcer healing is known, then this information can help to formulate appropriate management decisions ${ }^{17}$ and orient resources to those individuals with a poor prognosis.

We thank the study's nurse coordinators J V Cornwall and W Jones, Clinimed Ltd for the financial support of W Jones, the community nurses who helped with the study, and $\mathrm{O}$ Waldron for typing the manuscript.

1 Callam MJ. Prevalence of chronic leg ulceration and severe chronic venous disease in Western countries. Phlebology 1992;7(suppl 1):6-12.

2 Bosanquet N. Costs of venous ulcers: from.maintenance therapy to investment programmes. Phlebology 1992; 7(suppl 1):44-6.

3 Smith JM, Doré CJ, Charlett A, Lewis JD. A randomized trial of Biofilm dressing for venous leg ulcers. Phlebology 1992;7:107-13

4 Yao ST, Hobbs JT, Irvine WT. Ankle systolic pressure measurements in arterial disease affecting the lower extremities. Br I Surg 1969;56:676-9.

5 Cornwall JV. Diagnosis of leg ulcers. Fournal of District Nursing 1985;Sept 4-6,11

6 Cornwall JV, Dore CJ, Lewis JD. Leg ulcers: epidemiology and aetiology Brf Surg 1986;73:693-6.

7 Jones NAG, Webb PJ, Rees RI, Kakkar VV. A physiological study of elastic compression stockings in venous disorders of the leg. $\mathrm{Br} \mathcal{J}$ Sur 1980;67:569-72.

8 Cornwall JV, Dore CJ, Lewis JD Graduated compression and its relation to venous refilling time. $B M 7$ 1987;295:1087-90.

9 Dixon WJ, Brown MB, Engelman L Hill MA, Jennrich RI. BMDP starissical software manual. Vols 1, 2. Berkeley, California: University of California Press, 1988.

10 Kuk AYC. All subsets regression in a proportional hazards model. Biometrik 1984;71:587-92.

11 Christensen E. Multivariate survival analysis using Cox's regression model. Hepatology 1987;7:1346-58.

12 Stewart AJ, Leaper DJ. Treatment of chronic leg ulcers in the community: comparative trial of Scherisorb and Iodosorb. Phlebology 1987;2:115-21.

13 Kikta MJ, Schuler JJ, Meyer JP, Durham TR, Eldrup-Jorgensen T, Schwarcz $\mathrm{TH}$, et al. A prospective, randomized trial of Unna's boots versus hydroactive dressing in the treatment of venous stasis ulcers. I Vasc Surg 1988;7:478-83.

14 Colgan MP, Dormandy JA, Jones PW, Schraibman IG, Shanik DG Young $\cdot$ RAL. Oxpentifylline treatment of venous ulcers of the leg. $B M$ 1990;300:972-4.

15 Eriksson G. Bacterial growth in venous leg ulcers-its clinical significance in the healing process. In: Ryan TJ, ed. An environment for healing: the role of occlusion. London: Royal Society of Medicine, 1984:45-9.

16 Ormiston MC, Seymour MTJ, Venn GE, Cohen RI, Fox JA. Controlled tria of Iodosorb in chronic venous ulcers. BMF 1985;291:308-10.

17 DeFriend DJ, Edwards AT, McCollum C. Treatment of venous ulcerationwhen is surgical management indicated? Phlebology 1992;7(suppl 1):33-7.

(Accepted 8 September 1992)

\title{
Oral cancer in Scotland: changing incidence and mortality
}

\section{Gary J Macfarlane, Peter Boyle, Crispian Scully}

\section{Abstract}

Objectives-To determine the incidence of oral cancer in Scotland between 1960 and 1989 and oral cancer mortality from 1911 to 1989.

Setting-Data were obtained on oral cancer incidence from the information and statistics division of the Common Services Agency of the Scottish Health Service and mortality data from the office of the registrar general for Scotland.

Results-Mortality from intraoral cancers in Scotland substantially declined throughout this century until the mid-1970s. This trend, however, was then reversed, and fourfold increases in incidence were observed in younger age groups after 1960. Death rates in these younger age groups increased to levels previously recorded in the $1940 \mathrm{~s}$. These increases seemed to be cohort based and may therefore continue into the future.

Conclusions-Reasons for increasing rates among younger age groups are speculative and rely on combining knowledge about risk factors and available ecological data. Though increases in incidence at younger ages do not result in a large change in the number of cases diagnosed, possible similar increases continuing into older ages, when oral cancer is more common, will correspond to a much larger increase in the actual number of cases. Given that such a large attributable risk is associated with tobacco and alcohol, however, these increases may be preventable.

\section{Introduction}

There are wide geographical differences in the reported incidence rates of intraoral cancer. Tongue cancer in males is most common in India $(9.4$ per 100000 in Bombay), Brazil (7.4 per 100000 in São Paulo), and France (7.9 per 100000 in Doubs), and in females-although rates are much lower-the rates in Bombay (3.4 per 100000) and among Indians in Singapore $(3.3$ per 100000$)$ are considerably higher than those reported from cancer registries in othe countries. Those registries reporting the highest rates of tongue cancer also report high rates of mouth cancer. Low rates for both sites and in both sexes are reported from China, Japan, and northern European countries. At present Scotland has a relatively low incidence of mouth cancer (males 2.0 per 100000 females 0.8 per 100000 ) and tongue cancer (males 1.0 per 100000 ; females 0.6 per 100000 ) in internationa terms. $^{12}$

In the 1960s and 1970s there were several reports of a decrease in the incidence of mouth cancer in the United Kingdom ${ }^{3.5}$ and elsewhere, ${ }^{67}$ although these were based on data over relatively short periods. More recently an increasing incidence and mortality from tongue or mouth cancer, or both, has been noted in some countries, ${ }^{289}$ including Scotland, ${ }^{10}$ this change being particularly evident in young males.

The purpose of this report is to examine time trends in both the mortality from and incidence of intraora cancer in Scotland during this century.

\section{Material and methods}

Mortality data for Scotland are available aggregated by five year periods from 1911 to $1989 .{ }^{112}$ From 1951 data are grouped in five year age classes (0-4 years, $5-9$ years, up to $80-84$ years, and 85 years or over). Before this, however, the data were aggregated in age groups 
greater than five years. In order to maximise use of the data from 1911 to 1950 and allow formation of approximate birth cohorts of the same size cubic spline interpolation was used to estimate the number of cases occurring in each five year age group for the earlier time periods. ${ }^{13}$ Population estimates for Scotland are available by five year periods from 1911, and spline interpolation was again used to provide estimates of population by five year age classes when, between 1921 and 1930, these were not specifically available. We have considered data relating to intraoral cancernamely, tongue cancer (ICD (ninth revision) code 141) and mouth cancer (ICD codes 143-145). ${ }^{14}$ During this century there have been no major alterations to the ICD with respect to these malignancies which substantially affect interpretation of the data.

Having obtained estimates of both number of cases and population per time period in five year age classes, we calculated death rates standardised to the world population ${ }^{15}$ and truncated rates, limited to the age range $35-64$ years, ${ }^{16}$ for five year periods from $1911-5$ to 1981-5. In order to preserve the length of the periods (five years) the final period is from 1985 to 1989 . From these data approximate birth cohorts were established by assuming, for example, that those in the age group 40-44 years during 1960-4 were born in a period centred on 1920 and similarly that those aged 45-49 years during 1965-9 were also born in this time period, etc. In this way the incidence rates at different ages for the same birth cohort may be examined and changing rates with successive cohorts considered.

Data on the incidence of oral cancer in Scotland were obtained from the information and statistics division of the Scottish Health Services Common Services Agency. Data are available coded to the classification of the ICD and are available from 1959 to 1989 tabulated by sex and age at diagnosis. As with mortality the incidence data considered were with respect to tongue cancer (ICD code 141) and mouth cancer (codes 143-145). In order to calculate a stable rate data were analysed as a five year moving average. Thus the incidence for 1962 was calculated by using data from 1960 to 1964 and for 1963 by using data from 1961 to 1965, etc. Age standardised rates and truncated rates with data over five years were calculated as for mortality data, and (per 100000) in Scotland 1960-89 among men and women aged 35-64

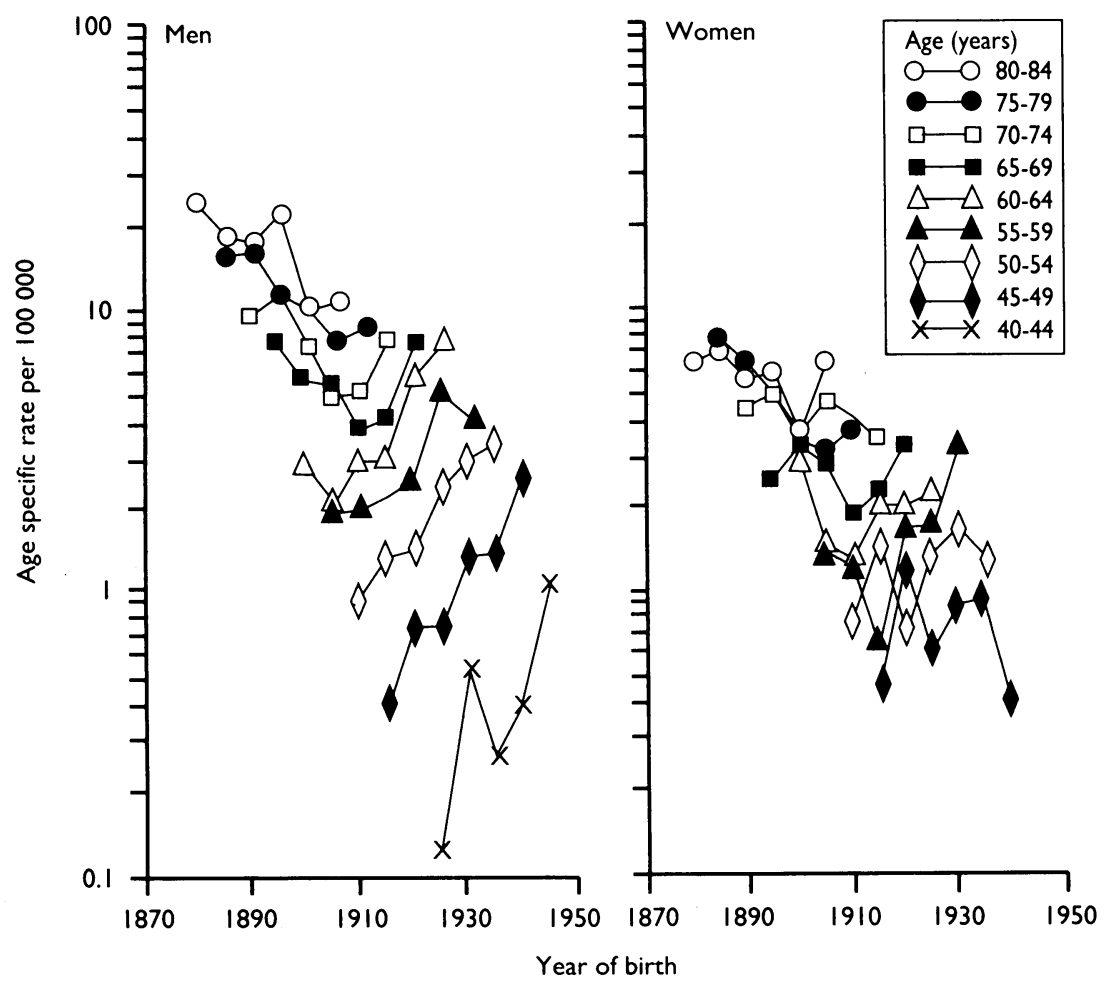

FIG 2-Tongue cancer incidence (per 100000 ) in Scotland among men and women by year of birth birth cohorts were formed in the manner described above.

\section{Results}

TONGUE CANCER INCIDENCE AND MORTALITY

Among men after a period between 1911-5 and 1931-5 when death rates from tongue cancer were high and stable there followed a period of consistently decreasing rates, from an age standardised mortality of 5.2 per 100000 in $1931-5$ to 0.5 per 100000 in $1981-5$. Only the most recent data had not followed this pattern, a small increase being recorded in the most recent period (1985-9). Analysis of the rates by age group and birth cohort showed a somewhat different picture. While rates in the oldest male age groups (70 years of age and over) had been steadily falling, rates in the younger age groups had been increasing . with successive cohorts born subsequent to around 1910. Examining the truncated mortality rate (age range 35-64) showed that death rates in this age group had almost doubled since 1976-80, to a rate of 1.3 per 100000 in 1985-9. Incidence data, although available over a shorter period, showed very clearly that a change had occurred. While there had been a modest increase in the age standardised incidence (males) from $1 \cdot 1$ per 100000 in $1960-4$ to 1.6 per 100000 in $1985-9$ there had been a more than threefold increase in the incidence in the age range 35-64 over the same period, from 0.9 to 3.0 per 100000 (fig 1 ).

The age specific incidence rates examined by birth $z$ cohort, in agreement with the trends in mortality, showed that those men born subsequent to around 1910 were experiencing increased rates of tongue cancer, which were rising with successive birth cohorts -for example, among men aged $60-64$ the age specific rate increased from $2 \cdot 6$ to $7 \cdot 6$ per 100000 over 20 years ! (fig 2).

Incidence and death rates for tongue cancer among women had been much lower when compared with rates among men throughout this century, but mortality had fallen from 0.7 per 100000 in $1911-5$ to $\mathbb{D}$ 0.3 per 100000 in 1985-9. There had been little change in the incidence of tongue cancer among women since 1960 and in the age range 35-64 years only a small increase, from 0.9 to 1.2 per 100000 (fig 1). Owing to the low rates of tongue cancer among women and the consequent highly variable rates no clear pattern was evident when rates were considered by year of birth (fig 2).

MOUTH CANCER INCIDENCE AND MORTALITY

Mouth cancer death rates in men were at their highest in the period 1931-5 with an age standardised mortality of 2.6 per 100000 , and thereafter the rates $N$ fell consistently to $0 \cdot 7$ per 100000 in 1971-5. Since $D$ then, however, there had been an increase in the all ages rate to $1 \cdot 1$ per 100000 . Again in men aged 35-64 the changes were more dramatic. There had been a N near quadrupling of the mortality, from 0.5 per $\frac{\omega}{\sigma}$ 100000 in $1971-5$ to 1.9 per 100000 in $1985-9$, equivalent to the prevailing rate in the 1940s. In women, while the age standardised mortality had been $\stackrel{\mathbb{S}}{\rightarrow}$ around 0.3 per 100000 throughout this century, the truncated rate had more than doubled since 1971-5, 0 resulting in a rate of 0.7 per 100000 , the highest $\mathbb{\mathbb { D }}$ recorded rate in Scotland for mouth cancer mortality in $\frac{\vec{D}}{\mathrm{D}}$ women in this age group (fig 3).

Incidence rates showed a similar trend. The age truncated rates had increased in men from 1.6 per 0 100000 in $1960-4$ to $5 \cdot 1$ per 100000 in $1985-9$ and in women from 1.3 to 1.9 per 100000 over the same period (fig 4). Examination of the incidence rates by birth cohort, while showing increases in rates in younger age groups and rates in older age groups still 


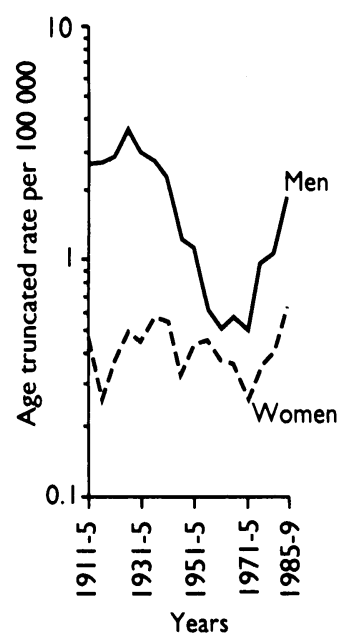

FIG 3-Mortality from mouth cancer (per 100000) in Scotland 1911-89 among men and women aged $35-64$

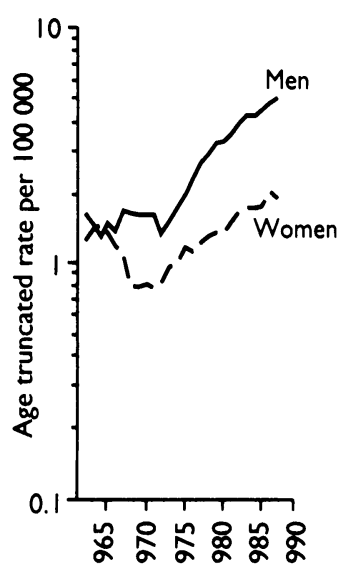

Mid-year of five year moving average

FIG 4-Mouth cancer incidence (per 100000) in Scotland 1960-89 among men and women aged 35-64 decreasing, did not show a clear change in rates with successive birth cohorts.

\section{Discussion}

There are several reasons for believing that the increases in mortality which were noted were likely to be real. Firstly, the changes seen in death rates for the two adjacent sites (tongue and mouth - that is, gum, floor of the mouth, cheek, vestibule, hard and soft palates, and other unspecified parts of the mouth) were very similar, the rates having initially decreased over 60 years and then having increased over the last 15 years. This suggests that misclassification between these sites is not a simple explanation of these changes If changes in incidence and mortality were solely due to misclassification, then we should expect to have observed an increase in frequency of occurrence at one site, corresponding to a decrease in frequency of occurrence at the other.

Secondly, although incidence data were available over much shorter periods, it is clear that the incidence of tongue and mouth cancer among both men and women was also rising. This was especially true for young adult males, in whom the incidence had trebled at both sites since around 1970. Thirdly, examination of both incidence and death rates for tongue cancer (males) by year of birth suggested the existence of a cohort effect-namely, that each successive birth cohort was experiencing increased incidence and death rates in each age group compared with previous cohorts, and it appeared that the increase in rates was first evident in the cohort born after 1910. If, for example, these increasing rates were as a result of changing practices in notification, then it would have been expected that this would apply to all age groups from a particular time period.

Finally, the changes in incidence and mortality, if real, were unlikely to be confined to Scotland. Indeed, increased incidence rates of tongue and mouth cancer have been noted in the United States (in younger age groups) and in Nordic countries ${ }^{29}$ and increased death rates from oral cancer in the United States ${ }^{8}$ and in many regions of Europe. ${ }^{17}$ Similar increased incidence rates in cohorts born after about 1910 have been noted in Denmark. ${ }^{18}$

While the changes noted above therefore appear to have been real, it is not clear why such changes had taken place. Tobacco smoking and alcohol have consistently been found to be important independent risk factors for intraoral tumours. ${ }^{19-24}$ The past few decades have seen an increase in alcohol consumption in developed countries. In the United Kingdom, though alcohol consumption per head of population is estimated to have fallen from around $25 \mathrm{~g}$ per person per day throughout the 19th century to a low of around $10 \mathrm{~g}$ between 1930 and $1960,{ }^{25}$ average consumption of ethanol increased by about $40 \%$ between 1960 and $1985 .{ }^{26} \mathrm{It}$ is likely that part of the increased incidence of intraoral cancer was due to this increase in alcohol consumption

There was, however, over the same period a decrease in tobacco consumption. ${ }^{27}$ It has been hypothesised ${ }^{8}$ that the increasing frequency of intraoral tumours may be due to the use of smokeless tobacco. Products such as snuff or chewing tobacco are estimated to be used now by $30 \%$ of the United States population between the ages of 8 and 18, and these products have been found to be associated with the development of oral cancer. ${ }^{28}$ However, though it is possible that the use of such products may be related to intraoral malignancies and may account for some of the increase in the United States, their use cannot explain the increasing rates currently seen. In Scotland the use of such products is not at present, and has not previously been, widespread.

No other important risk factor for oral cancer in Western countries has been identified to date that could readily explain the increases noted in the occurrence of oral malignant disease, although the lack of such studies with sufficient numbers of subjects in young age groups means that knowledge of risk factors and their importance is derived from disease occurrence in older subjects. It would be important, therefore, to more accurately assess and quantify risk factors for disease in the younger age groups, among whom the current increase in incidence and mortality has been recorded.

We thank Dr Roger Black of the information and statistics division, Scottish Health Services Common Services Agency, Edinburgh, for supplying oral cancer incidence data for Scotland

1 Muir C, Waterhouse J, Mack T, Powell J, Whelan S, eds. Cancer incidence in five contments. Vol 5. Lyons: International Agency for Research on Cancer, 1987. (IARC Scientific Publication No 88.)

2 Hakulinen T, Andersen AA, Malker B, Pukkala E, Schou G, Tulinius H. Trends in cancer incidence in the Nordic countries. Acta Pathologica Scandinavica 1986;94(suppl 228):30-1

3 Russell MH. Diverging sex-morbidity trends in cancer of the mouth: hospital morbidity study. $B M \mathcal{F}^{1} 1955 ; \mathrm{ii}: 823-7$.

4 Binnie WH, Cawson RA, Hill GB, Soaper AE. Oral cancer in England and Wales. A national study of morbidity, mortality, curability and related factors Wales. A national study of morbidity, mortality, curability and related factors. Subjects, No 23.)

5 Easson EC, Palmer MK. Prognostic factors in oral cancer. Clin Oncol 1976;2:191-202.

6 Tan KN. Oral cancer in Australia. Aust Dent F 1969;14:50-6.

7 Svejda J, Kosut V. Epidemiology of malignant tumours with special regard to the orofacial region. Neoplasma 1971;18:193-6.

8 Depue P. Rising mortality from cancer of the tongue in young white males. N Engl f Med 1986;315:647.

9 Davis $\mathbf{S}$, Severson RK. Increasing incidence of cancer of the tongue in the United States among young adults. Lancet 1987;i:910-1.

10 Macfarlane GJ, Boyle P, Scully C. Rising mortality from cancer of the tongue in Scottish white males. Lancet 1987;ii:1912.

11 Case RAM, Coghill C, Davies JM, Harley JL, Hytten CA, Pearson JT, et al. Serial mortality tables. Neoplastic diseases. Vol 4. Scotland, 1911-1970. London: Institute of Cancer Research, 1976.

12 Registrar General for Scotland. Annual report. Edinburgh: HMSO, 1990

13 Schifflers E, Smans M, Muir CS. Birth cohort analysis using irregular crosssectional data: a technical note. Statistics in Medicine 1985;4:63-75.

14 World Health Organisation. Manual of the international statistical classification of diseases, injuries and causes of death. Ninth revision. Geneva: WHO, 1977 .

15 Doll R, Payne P, Waterhouse JAH. Cancer incidence in five continents. Vol 1 Berlin: Springer, 1966

16 Doll R, Cook P. Summarising indices for comparison of cancer incidence data. Int 9 Cancer 1967;2:269-79.

17 La Vecchia C, Lucchini F, Negri E, Boyle P, Maisonneuve P, Levi F. Trends of cancer mortality in Europe 1955-1989 I. Digestive sites. Eur $\mathcal{Y}$ Cancer 1992;28:132-235.

18 Moller $\mathrm{H}$. Changing incidence of cancer of the tongue, oral cavity and pharynx in Denmark. F Oral Pathol Med 1989;18:224-9.

19 Blot WJ, McLaughlin JK, Winn DM, Austin DF, Greenberg RS, PrestonMartin $S$, et al. Smoking and drinking in relation to oral and pharyngeal Martin S, et al. Smoking and drinkit

20 Brugere J, Quenel P, Leclerc A, Rodriguez J. Differential effects of tobacco and alcohol in cancer of the larynx, pharynx and mouth. Cancer 1986;57: $391-5$

21 Graham S, Dayal H, Rohrer T, Swanson M, Sultz H, Shedd D, et al Dentition, diet, tobacco and alcohol in the epidemiology of oral cancer I Natl Cancer Inst 1977;59:1611-8.

22 Keller AZ, Terris $M$. The association of alcohol and tobacco with cancer of the mouth and pharnyx. Am $\mathcal{F}$ Public Health 1965;55:1578-85.

23 Merletti F, Boffetta P, Ciccone G, Mashberg A, Terracini B. Role of tobacco and alcoholic beverages in the etiology of cancer of the oral cavity/ oropharynx in Torino, Italy. Cancer Res 1989;49:4919-24.

24 Wynder EL, Bross JJ, Feldman RM. A study of the etiologic factors in cancer of the mouth. Cancer 1957;10:1300-23.

25 Spring JA, Buss DH. Three centuries of alcohol in the British diet. Nature 1977;270:567-72

26 International Agency for Research on Cancer. Alcohol drinking. IARC Monogr Eval Carcinog Risks Hum 1988:44:41-69.

27 Wald NJ. Smoking. In: Vessey MP, Gray M, eds. Cancer risks and prevention. Oxford: Oxford University Press, 1985:44-67.

28 Winn DM, Blot WJ, Shy CM, Pickle LW, Toledo A, Fraumeni JF, Snuff dipping and oral cancer among women in the southern United States. $N$ Engl IMed 1981;305:745-9.

(Accepted 20 August 1992) 